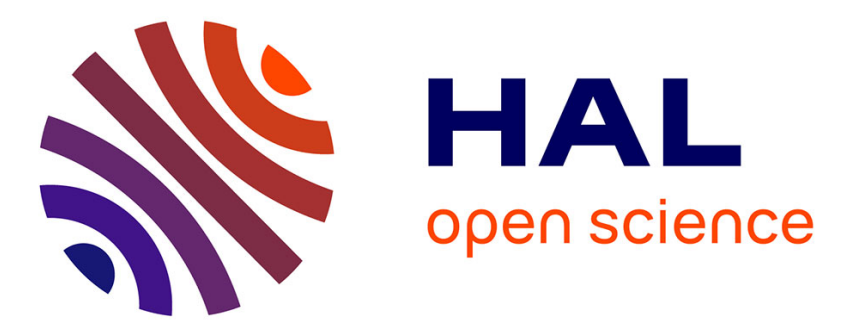

\title{
Improvement of a cirrus correction empirical method with sentinel-2 data
}

\author{
Sandra Salgado, Laurent Poutier, Sandrine Mathieu, Xavier Briottet
}

\section{To cite this version:}

Sandra Salgado, Laurent Poutier, Sandrine Mathieu, Xavier Briottet. Improvement of a cirrus correction empirical method with sentinel-2 data. IGARSS 2020 IEEE International Geoscience and Remote Sensing Symposium, Sep 2020, Waikoloa (Online), United States. hal-02987664

\section{HAL Id: hal-02987664 https://hal.science/hal-02987664}

Submitted on 4 Nov 2020

HAL is a multi-disciplinary open access archive for the deposit and dissemination of scientific research documents, whether they are published or not. The documents may come from teaching and research institutions in France or abroad, or from public or private research centers.
L'archive ouverte pluridisciplinaire HAL, est destinée au dépôt et à la diffusion de documents scientifiques de niveau recherche, publiés ou non, émanant des établissements d'enseignement et de recherche français ou étrangers, des laboratoires publics ou privés. 


\title{
IMPROVEMENT OF A CIRRUS CORRECTION EMPIRICAL METHOD WITH SENTINEL-2 DATA
}

\author{
Sandra Salgado ${ }^{1,2}$, Laurent Poutier ${ }^{l}$, Sandrine Mathieu ${ }^{3}$, Xavier Briottet $^{l}$ \\ ${ }^{1}$ ONERA - The French Aerospace Lab, 2 Avenue Edouard Belin, 31055 Toulouse Cedex 4, France \\ ${ }^{2}$ Université Fédérale Toulouse Midi-Pyrénées, 41 Allée Jule Guesde, 31013 Toulouse Cedex 6, \\ France \\ ${ }^{3}$ Thales Alenia Space, 5 Allée des Gabians, 06156 Cannes la Bocca Cedex France
}

\begin{abstract}
The atmospheric correction of remote sensing data in the reflective domain is today very well controlled under clear sky conditions. However, cirrus clouds represent $2 / 3$ of the global terrestrial cover, making several images unusable. Gao and $\mathrm{Li}$ [5] proposed an empirical method of thin cirrus correction. The method shows very good results on dark surfaces but presents bias higher than 0.02 when the surface becomes too reflective and the cirrus too thick. In addition, it only corrects for the upwelling path [7]. Simulations show that the presence of cirrus on the sun-to-ground path has a significant influence on the received signal and must also be corrected. This paper shows that considering the transmission term of the cirrus of the upwelling and downwelling paths improves the results in the red-edge but also the SWIR, with an RMSE divided by 2 .
\end{abstract}

Index Terms - Correction, cirrus, Sentinel-2

\section{INTRODUCTION}

The observation and understanding of the Earth has become very important. More and more instruments have been developed to study it, including optical sensors, like AVIRIS, MODIS, Landsat or Sentinel-2. These sensors provide more (hyperspectral) or less (multispectral) bands, covering different parts of the spectrum. They deliver a radiance signal coming from the Sun and scattered by the surface to the sensor. Along this path, the solar radiation propagates through the atmosphere, which disturbs the signal (absorption and scattering). It is therefor necessary to overcome these effects in order to retrieve a signal only depending on the surface: the reflectance. This step is called the atmospheric correction. The latter is today very well understood in clear sky condition.

But clouds cover $68 \%$ of the global surface, modifying the signal too. They can be divided into two main categories: water clouds, opaque, scattered, low in the atmosphere; and ice clouds (cirrus type): high in the atmosphere, extended and optically thin, they let glimpse the underlying surface. This paper focus on cirrus clouds.
Their high altitude allowed Gao et al. [2] put forward a detection method using the strong absorption band of water vapor, located at $1.38 \mu \mathrm{m}$. This method is very useful for sensors without thermal bands. Thanks to their transparency, Gao and al (1998) proposed a first empirical correction method for thin cirrus, between 0.4 and $1.0 \mu \mathrm{m}$ [3] that they later extend to the SWIR $([0.4-2.5 \mu \mathrm{m}])$ for Landsat [5].

This method has been quantitatively validated with Sentinel-2 data, with an accuracy of $0.02 \mathrm{rms}$ on the apparent reflectance, particularly for dark surfaces [7]. But when the surface becomes more reflective and cirrus thicker, the bias increases, especially on the red-edge spectral domain $([0.7-0.9 \mu \mathrm{m}])$.

This paper first recalls the Gao' correction method then discusses and describes how the results can be improved using simulations.

\section{GAO METHOD}

Gao and al. [3] modeled the Earth-atmosphere system by 2 superposed plan and parallel layers: a virtual surface (including the surface and all the atmosphere - water-vapor, water clouds, aerosols) and a layer of cirrus clouds. Using the classic formula of radiative transfer applied to the cirrus layer, the measured apparent reflectance is written:

$$
\rho_{\text {measured }}^{*}(\lambda)=\rho_{c}^{*}(\lambda)+T_{c} \rho_{v S}^{*}(\lambda) \frac{1}{1-S_{c} \rho_{v S}^{*}(\lambda)}
$$

where $\rho_{c}^{*}(\lambda)$ denotes the apparent reflectance of the cirrus cloud, $\mathrm{T}_{\mathrm{c}}$ the total transmission (diffuse + direct, up and down) through the cirrus, $\rho_{v s}^{*}(\lambda)$ the apparent reflectance of the virtual surface, and $S_{c}$ the spherical albedo of the cirrus. From this equation some simplifications are made: the coupling term is simplified, assuming $\mathrm{S}_{\mathrm{c}}$ is weak $(<0.2)$ and, total absorption being negligible for thin cirrus, the transmission is put equal to unity and, $\rho_{c}^{*}(\lambda)$ is proportional to the signal at $1.38 \mu \mathrm{m}$ so the reflectance corrected from the presence of thin cirrus then expresses as:

$$
\rho_{v s}^{*}(\lambda)=\rho_{\text {measured }}^{*}(\lambda)-\frac{\rho_{c}^{*}(1.38 \mu m)}{K_{a}(\lambda)}
$$


With $\mathrm{K}_{\mathrm{a}}(\lambda)$ accounting for the residual water vapor absorption in the $1.38 \mu \mathrm{m}$ band. It is estimated using a scatterplot between $\rho_{c}^{*}(1.38 \mu m)$ and $\rho_{c}^{*}(\lambda)$. These coefficients depend on the scene, the cirrus, and on solar and view angles. The linear regression slope is obtained with the Gao' method [4], which consists in, for each bin of the cirrus apparent reflectance, taking the closest points to the minimum value of the apparent reflectance in the band $\lambda$.

\section{IMPROVEMENT METHOD}

The previously described method has shown good results with an overall accuracy of the order of $0.02 \mathrm{rms}$ but degraded with an increase of the cirrus optical thickness, in particular in the red-edge and the SWIR. This is particularly noticeable on reflective surfaces. In order to better understand this phenomenon, which we supposed to be due to the fact that the downward path is not taken into account, the images used for the validation were analyzed and simulations were carried out.

\subsection{Data}

To validate our hypotheses, the same data are used as those used to validate Gao's method [7]. They are composed of pairs of images from the Sentinel-2 multispectral sensor [8], one acquired under clear sky conditions, used as a reference, and the other one with the presence of cirrus clouds. The two images are acquired at two very close dates taken under the same acquisition conditions ( $\leq 5$ days), so that the ground scene can be assumed almost invariant, to have comparable images. The two selected pairs of images are described in the Table 1.

Table 1: Characteristics of the different Sentinel-2 images studied

\begin{tabular}{|c|c|c|c|c|}
\hline & \multicolumn{2}{|c|}{ La Crau (France) (T31TFJ) } & \multicolumn{2}{c|}{$\begin{array}{c}\text { Portugal } \\
\text { (T29TNF) }\end{array}$} \\
\hline & $\begin{array}{c}\text { Clear sky } \\
\text { image }\end{array}$ & Cirrus image & $\begin{array}{c}\text { Clear sky } \\
\text { image }\end{array}$ & Cirrus image \\
\hline Satellite & S2B & S2A & S2A & S2A \\
\hline $\begin{array}{c}\text { Date + UTC } \\
\text { time }\end{array}$ & $\begin{array}{c}07 / 29 / 2018- \\
10 \mathrm{~h} 30\end{array}$ & $\begin{array}{c}08 / 03 / 2018- \\
10 \mathrm{~h} 30\end{array}$ & $\begin{array}{c}10 / 25 / 2017- \\
11 \mathrm{~h} 33\end{array}$ & $\begin{array}{c}10 / 22 / 2017- \\
11 \mathrm{~h} 21\end{array}$ \\
\hline $\begin{array}{c}\text { Solar zenith } \\
\text { angle }\end{array}$ & $28.8^{\circ}$ & $29.9^{\circ}$ & $54^{\circ}$ & $165.3^{\circ}$ \\
\hline $\begin{array}{c}\text { Solar azimuth } \\
\text { angle }\end{array}$ & $145.0^{\circ}$ & $146.2^{\circ}$ & $168.7^{\circ}$ & $6.0^{\circ}$ \\
\hline $\begin{array}{c}\text { Zenithal angle } \\
\text { of view }\end{array}$ & $7.2^{\circ}$ & $7.1^{\circ}$ & $9.0^{\circ}$ & $6.0^{\circ}$ \\
\hline $\begin{array}{c}\text { Azimutal } \\
\text { angle of view }\end{array}$ & $106.5^{\circ}$ & $105.5^{\circ}$ & $287.3^{\circ}$ & $103.8^{\circ}$ \\
\hline \multicolumn{2}{|c|}{} & & & \\
\hline
\end{tabular}

\subsection{Data analysis - phenomenology}

Fig.1 illustrates spectra extracted for 3 different zones of the La Crau image. For each case, is illustrated the spectra of one pixel on the clear sky image, the cirrus image and the corrected image. On the Fig.1a case, as in most cases, an almost spectrally offset occurs, as expected from formula

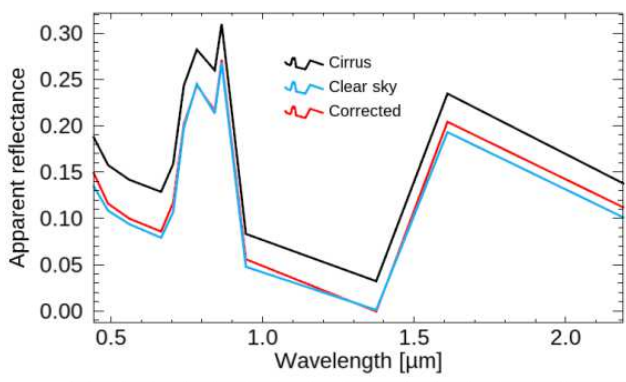

(a)
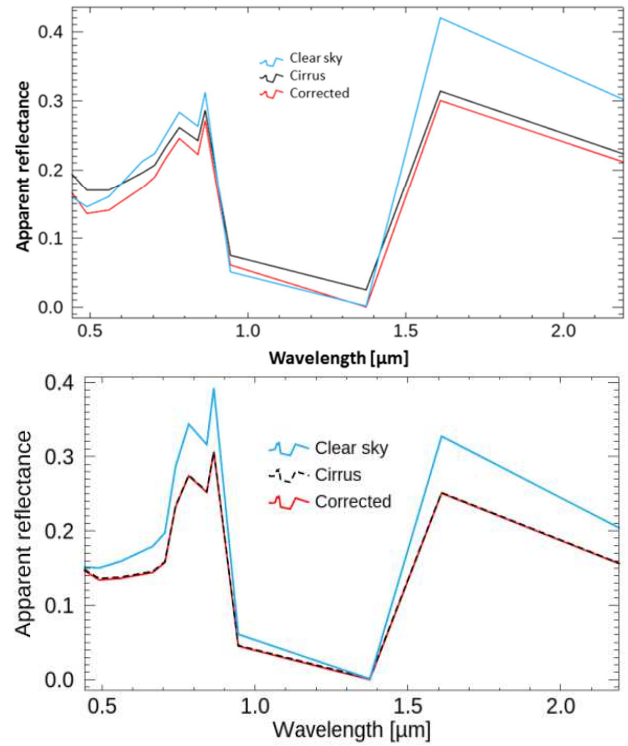

(c)

Figure 1 : Spectra of a same pixel extract from La Crau Sentinel-2 images: the clear sky image, the cirrus image and the corrected image. (a): offset observe between the cirrus and the clear sky images. (b): the cirrus here have a different impact on the signal in the red-edge region. (c): no cirrus being detected $\left(\rho^{*}(1.38 \mu \mathrm{m})=0\right)$, no correction is applied.

(2), so the corrected signal correspond to the clear sky signal. On the other hand, it happens, in the red-edge and SWIR, that the presence of a cirrus makes the signal weaker than in the case of clear sky (Fig.1b). This latter case exhibits an over-correction. In the Fig.1c case, no cirrus is detected $\left(\rho_{c}^{*}(1.38 \mu m)=0\right)$ so no correction is applied according to the formula (2). But the clear sky signal is higher than the cirrus one. This region corresponds to a region where there is a cirrus on the descending path. This one therefore has a significant influence on the signal.

Simulations were then carried out in order to further analyze and propose an improvement of the model.

\subsection{Simulations}

To understand these limitations, simulations were carried out using COMANCHE tool [6]. When restricted to homogeneous scenes, this simulation tool basically runs MODTRAN radiative transfer code and provides the various radiative terms driving the at-sensor signal. The simulations 


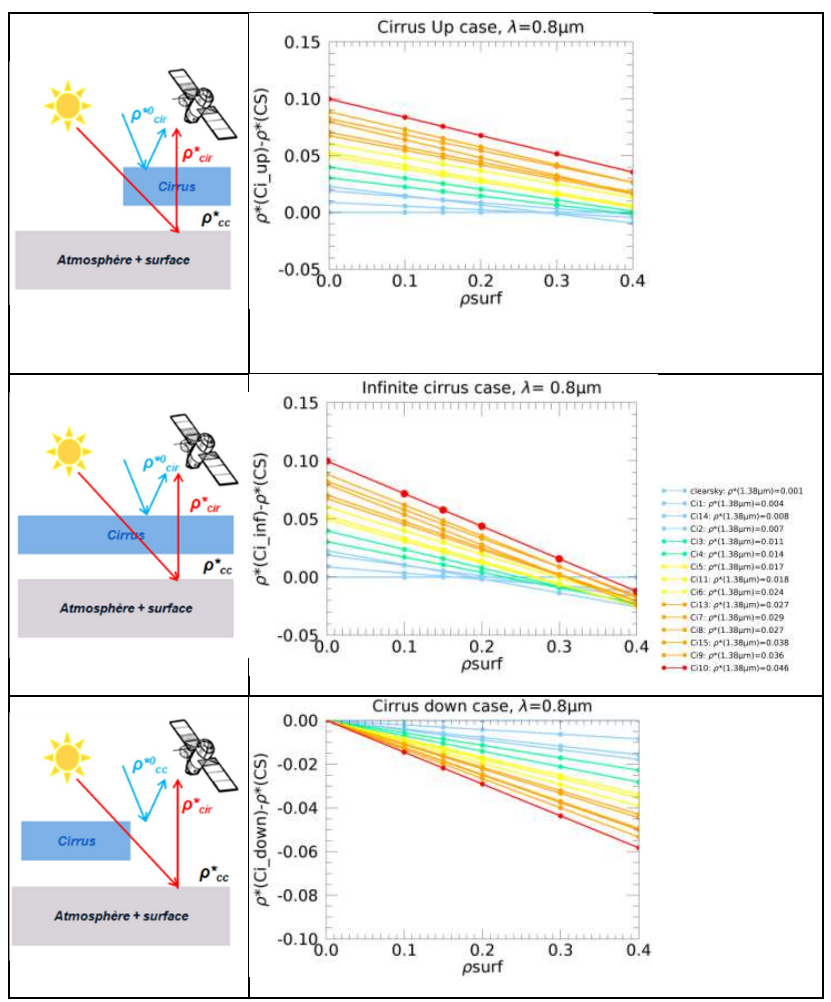

Figure 2: Configuration of simulations and result of the difference between the signal with cirrus condition and clear sky condition, for different surfaces and cirrus

used the acquisition parameters related to La Crau and Portugal images (Table 1), and several optical thickness of cirrus. Three scenarios are played corresponding to the location of the cirrus on the down- or up-ward paths (Fig.2):

- Cirrus Up (CU): Downward path with clear sky / Upward path with cirrus

- Infinite cirrus (IC): Downward and upward paths with cirrus (same cirrus for the 2 paths)

- Cirrus Down (CD): Downward path with cirrus / Upward path with clear sky

The right part of Figure 2 shows the difference between the apparent reflectance in presence of cirrus and that under clear sky as a function of surface reflectance, for each scenario. The first case (CU), which corresponds to Gao's model, shows that the cirrus signal is always higher than clear sky signal. On the 2 other cases, with a cirrus on the downward path, an inversion is observed, with a cirrus signal lower than the clear sky signal. These 3 situations correspond to the observations in Figure 1. The more reflective the surface and the thinnest the cirrus, the more likely it is to be over-corrected. Thus, not taking into account the downward path can lead to an error of up to 0.06 . This indicates the necessity of taking into account the downward path in the correction process.

Further, simulated transmission of cirrus is shown to be rather of the order of $0.7-0.8$, therefore not negligible, and it is correlated with the apparent reflectance at $1.38 \mu \mathrm{m}$ by empirical polynomial model. Then we can use the formula:

$$
\rho_{v S}^{*}(\lambda)=\left[\rho_{\text {measured }}^{*}(\lambda)-\frac{\rho_{c}^{*}(1.38 \mu m)}{K_{a}(\lambda)}\right] \cdot \frac{1}{T_{c}}
$$

\subsection{Validation method}

To validate the method we want to find in the image the different situations presented on Figure 2. For that, the pairs of image are used and the different cirrus of the scene, according their optical thickness, and all pixels with a signal in presence of cirrus lower than in the clear sky image, in the red-edge, have been illustrated in color and grey, respectively (Fig. 3). Patterns similar to those of cirrus, but shifted in the direction of illumination are observed, which confirms that the presence of a cirrus on the downward path has a significant impact on the signal. The model of Gao is therefore limited to the case where the cirrus is only on the rising path. From there, several areas of interest (ROI) were chosen as shown in Figure 3 for the case of La Crau, corresponding to the various situations presented in Figure 2. The correction of Gao and $\mathrm{Li} \mathrm{[5]} \mathrm{is} \mathrm{then} \mathrm{compared} \mathrm{with}$ two methods of taking into account the transmission.

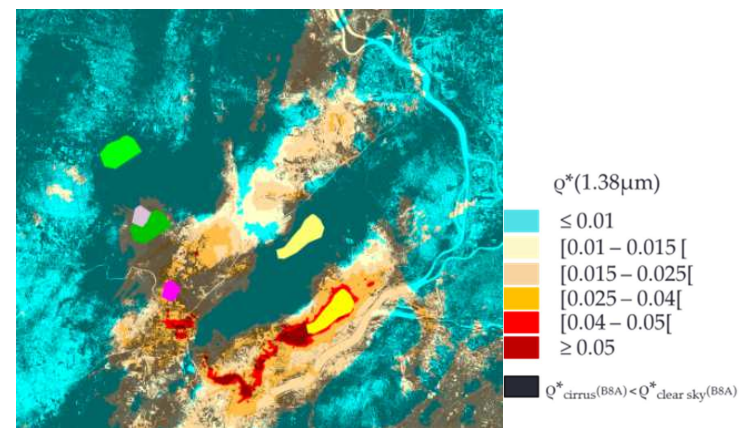

Figure 3: Different thickness of cirrus and illustration, in grey, of the pixels over-corrected for La Crau. The cirrus patterns are found in these over-corrected pixels. The colored shapes couple represent the ROIs studied and the cirrus zones on the corresponding descending path. The green and yellow ROIs corresponding to the $\mathrm{CD}$ case and the pink ROI to the IC case.

In order to know the position of the cloud shadow from the single cirrus image, it is mandatory to accurately know the height of the cloud. However the height is not known in our case. The position of the shadow is therefore roughly estimated, visually, thanks to the couple of image, and remains imprecise. We estimated the transmission by 2 different ways:

- A pixel by pixel correction, by manually estimating the $\Delta \mathrm{x} / \Delta \mathrm{y}$ displacement for each ROI (knowing the "shadow" areas thanks to the clear sky image).

- A correction by calculating an average transmission on the cirrus of the downward path. This average transmission is then applied to all the pixels of the corresponding ROI. 

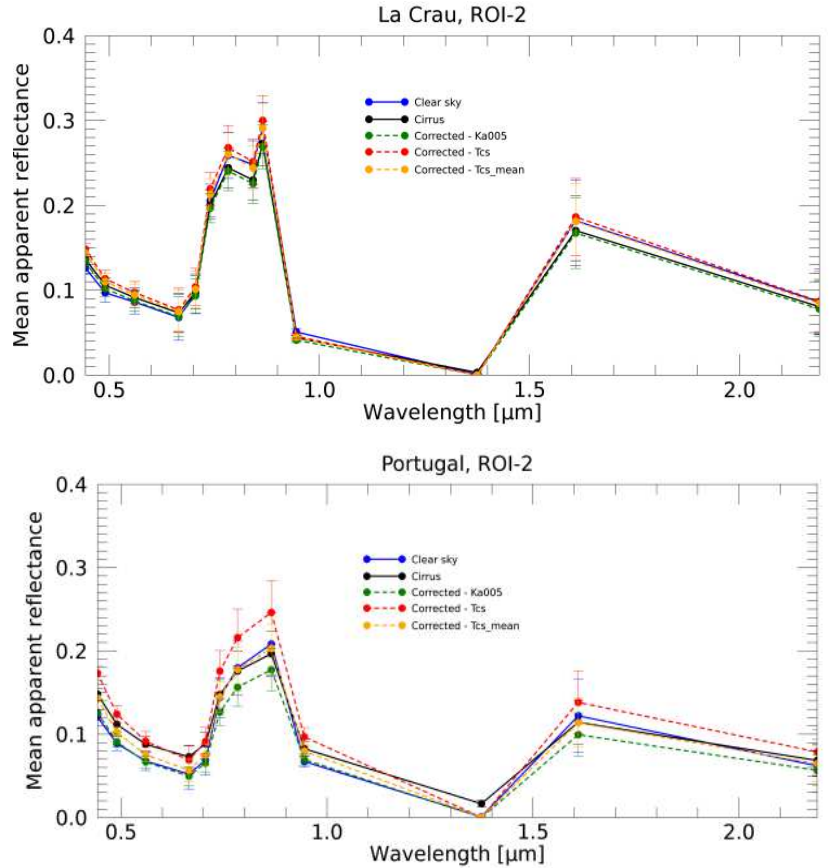

Figure 4 : Mean apparent reflectance of the cirrus image (black), the clear sky image (blue), the corrected image with Gao and al. method (green), the corrected image with the transmission taken into account, pixel by pixel (red), average transmission (orange). For one study area of La Crau (top) and Portugal (bottom)

The comparison between the image corrected from cirrus to the clear sky image is achieved by calculating the RMSE of the difference between the two apparent reflectances.

\section{RESULTS}

Figure 4 shows the mean apparent reflectance for 2 studied areas and for each case: with cirrus, in clear sky, and after the different corrections. The La Crau case has clear sky on the upwelling path and moderately thick cirrus on the downward path while the Portugal area has cirrus clouds on both paths. One can observe, as on Figure 1, that by applying Gao and al. method, there is either no correction, or an over-correction. On the other hand, assessing the transmission (red and orange curves) make it possible to get closer to the clear sky curve, in the red-edge but also in the SWIR, which has a similar behavior. The RMSE are divided by 2 . In the case of $\mathrm{La} \mathrm{Crau}$, the method that works best is "pixel by pixel" while the average method works best in the case of Portugal. This is because the estimated $\Delta x / \Delta y$ shift is not accurate enough for the second case.

\section{CONCLUSION}

The empirical cirrus correction method proposed by Gao and $\mathrm{Li}$ [5] allows the clear sky signal to be found with an accuracy of less than 0.02 for dark surfaces (water type) and for certain continental surfaces [7]. On the other hand, when the reflectance of the surfaces becomes too high and a cirrus is present on the sun-surface path, the method over-corrects the signal. Pairs of Sentinel-2 images, as well as simulations, were then used to understand and to overcome this limitation. This made it possible to understand that the downward path should also be taken into account using the transmission. The downward path transmission is assessed using an empirical relation to $\rho^{*}(1.38 \mu \mathrm{m})$. Taking this parameter into account clearly improves the result in the red-edge but also in the SWIR with twice the accuracy. On the other hand, errors remain mostly because the cirrus taken into account on the downward path is not necessarily the right one.

In order to overcome this and be able to correct the cirrus image without a reference image, it would be necessary to be able to know the height of the cloud either from the single optical image, or using a complementary instrument delivering simultaneously the information. By knowing solar angles it would then be possible to precisely deduce the location of each pixel impacted by the cirrus. And even then there will always be limits for the edges of the image because cirrus can be out off field of view and so their impact is not taking into account.

\section{REFERENCES}

[1] A.Berk, G.P. Anderson, P.K. Acharya, J.H. Chetwynd, L.S. Bernstein, E.P. Shettle, M.W. Matthew, ans S.M. Alder-Golden, "MODTRAN-4 user's manual", 2000

[2] B-C. Gao and A.F.H. Goetz, "Cirrus cloud detection from airborne imaging spectrometer data using the $1.38 \mu \mathrm{m}$ water vapor band”, Geophysical Research Letter 20, 301-304, 1993

[3] B-C. Gao, Y.J. Kaufman, W. Han, and W.J.Wiscombe, "Correction of thin cirrus path radiance in the 0.4-1.0 $\mu \mathrm{m}$ spectral region using the sensitive $1.38 \mu \mathrm{m}$ cirrus detecting channel" Journal of Geophysical Research, 103, 32.169-32.176, 1998.

[4] B-C. Gao, P. Yang, W. Han, R-R. Li and W.J. Wiscombe, "An algorithm using visible and $1.38-\mu \mathrm{m}$ channels to retrieve cirrus cloud reflectances from aircraft and satellite data", IEEE, Vol.40, N0.8, August 2002

[5] B.C. Gao and R.R. Li, "Removal of thin cirrus scattering effects in Landsat 8 OLI images using the cirrus detecting channel”, Remote Sensing 9, 834, 2017

[6] C. Miesch, L. Poutier, V. Achard, X. Briottet, X. Lenot, Y. Boucher. «Direct and Inverse Radiative Transfer Solutions for Visible and Near-Infrared Hyperspectral Imagery », IEEE TGARS, Vol. 43, $\mathrm{N}^{\circ} .7$, pp 1552-1562, July 2005

[7] S. Salgado, L.Poutier, X. Briottet, S. Mathieu, « Validation of an empirical method for thin cirrus correction with Sentinel-2 data", Proceedings of SPIE Vol. 11152, 111520H, 2019 
[8] “Sentinel-2, User Handbook”, ESA, 2015 